\title{
LOGISTICS SUPPORT TO ELECTRONIC COMMERCE IN BRAZIL: TRENDS AND CONSTRAINTS
}

\author{
Antonio G.N. Novaes \\ Macul Chraim \\ Federal University of Santa Catarina \\ Department of Industrial Engineering \\ Florianópolis, SC, BRAZIL \\ email:novaes@eps.ufsc.br
}

\begin{abstract}
The FedEx pioneering hub-and-spoke courier service launched in the US thirty years ago has positively impacted commerce in North America by reducing inventory levels, expediting express shipments, and fostering the rapid growth of new e-commerce enterprises. In Brazil, the trend is to concentrate ecommerce on large firms, with a long tradition in retail operations. The nonexistence of high-standard distribution services is restraining the entrance of smaller firms in the process. We examine in the paper the possible utilization of excess hold capacity in inter-city bus lines as a logistics basis to express shipments in Brazil. The challenge is to establish an effective logistics network linking bus firms in order to achieve the required standards.
\end{abstract}

\section{INTRODUCTION}

Although Brazil, with 157 million inhabitants, has only 3.2 million Internet users, of which $24 \%$ are potential e-commerce consumers, future perspectives for the electronic commerce are positive. By 2003, about 5.7 million Internet users are expected, from which $35 \%$ will probably be e-commerce consumers (Vassalo, 1999). But, in order to satisfy customers' expectations, which are more demanding in the e-commerce, a few obstacles must be removed in the near future.

One of the main problems to be solved is the logistics support to the electronic commerce (Moakley, 1999; Rebouças, 2000). The non-existence in the country of high-standard, nation-wide, express-delivery services such as FedEx, UPS and DHL, restrains the growth of the e-business, forcing the larger companies to operate private fleets at higher costs, and making it difficult the entry of smaller firms in the process. We discuss in this paper the challenges to adequately operate dot-com firms in Brazil from a logistics point of view.

We concentrate our attention to the $\mathrm{B} 2 \mathrm{C}$ e-commerce, letting aside the $\mathrm{B} 2 \mathrm{~B}$ and $\mathrm{C} 2 \mathrm{C}$ modalities. First, we discuss in general terms the challenges that the ecommerce is imposing to the Supply Chain Management. Next, we try to typify the 
prospective patrons of the $\mathrm{B} 2 \mathrm{C}$ e-commerce in Brazil. This is an important matter when defining appropriate logistics strategies to satisfy customers' needs. Third, we analyze the logistics services available in Brazil that are of interest to the ebusiness. Finally, we discuss the possibilities of implementing an efficient nationwide express-delivery service in the country, capable of a satisfactory response to the basic logistics needs of the e-commerce in Brazil.

\section{LOGISTICS CHALLENGES IMPOSED BY THE e-COMMERCE}

Despite the cliché that the Internet is the "death of geography", place and physical displacement still matters. These elements matter less today than a decade ago, however. This is particularly true for the growing number of enterprises in which the strategic utilization of information plays a key role in bringing products to market (Moon, 2000).

The B2C e-commerce has close relationships with the retail industry. They differ, however, in the number and types of intermediaries. The intermediary basic function is to improve the efficiency with which products and services move through the supply channel (Moon, 2000). The traditional logistics network has been intimately associated with space. The number and location of warehouses and distribution centers, for instance, have been dealt with as an important strategic problem in Logistics courses. In the e-commerce place still matters, of course. But it matters less today than a decade ago.

Most of the market inefficiencies that intermediaries have had to deal with in traditional commerce have involved geographic displacements, introduced in the process by the distance that separates buyers and sellers (suppliers to retailers, retailers to consumers, etc). As an utmost objective of the e-commerce, the ideal situation is the one that occurs when physical products will be carried from the manufacture to the final customer, avoiding all intermediate movements. Hence, non value-adding displacements tend to be completely eliminated from the supply chain. Of course, whenever a physical displacement is eliminated, a cost is cut off from the supplying process, and thus, e-commerce logistics tends to be less costly in some aspects, although other typical functions might be more expensive.

In addition to reducing physical displacement costs, e-commerce firms are reconsidering who will absorb the margins, hence eliminating as many intermediaries as possible. This process can be regarded as a "desintermediation" (Moon, 2000). In firms deeply inserted in the Web, as Dell Computers and Amazon, most of the channel functions involving only the treatment of information, including product information, customer orders, customers inquiries, and others, are handled effectively via the Web. But these firms, as mentioned, have also managed to remove many of the inefficiencies associated with physical handling of components and products along the value chain. As a result, many intermediary functions were reduced (wholesalers, retailers, media advertising), increasing the margins of the dot-com firm. Additionally, the intermediaries that have remained in the chain, such as suppliers, transport operators and logistics service providers, are being forced to offer higher quality services in order to maintain their market positions.

In the $\mathrm{B} 2 \mathrm{C}$ e-commerce, logistics managers are coping with different operating 
practices and demands when compared to the existing scenario a decade ago (Aldrich, 1999). First, single items are replacing bulk shipments. In the past, the movement of products was done in cases and pallets. Orders were equally taken in larger quantities. Now, in the $\mathrm{B} 2 \mathrm{C}$ e-commerce, the handling of individual units (SKUs, in the retail jargon) is the rule, not the exception. Although, in principle, this new procedure requires the same basic handling equipment used before, such as carousel racks, flow racks and conveyors, the number of operations tends to increase significantly. On the other hand, since individual items are not protected by racks and boxes any more, additional care must be paid when handling the products. Furthermore, in supermarket purchases via Internet, for example, it is common to have orders with a mix of non-perishable and perishable products (meat, vegetables, frozen products). This involves the separate treatment of the same order, implying additional care and coordination.

Second, in the traditional commerce it has been acceptable to deliver products to customers within 24 to 72 hours. For most dot-com firms, however, these standards are not satisfactory any more (Caltagirone, 2000). In special for grocery products, consumers expect immediate delivery. In many cases the customer is not satisfied to know that his or her supermarket order will arrive the same day, without specifying the hour. Thus, the previous definition of a time window for the delivery is sometimes mandatory. Of course, this requirement put additional constraints to the operational logistics planning. Note that the logistics planning at the warehouse is a dynamic process in this case, since orders are frequently submitted online. This is quite different from the situation prevailing in the traditional commerce, in which such operations could be planned beforehand, at least with 24-hour anticipation.

Third, customer demands in the e-commerce have been extremely difficult to forecast. Many entrepreneurs, after putting up a Web site to sell some kind of product, soon had their shipping department jammed with orders, sometimes much more than they could fulfil. This situation may lead to a deficient logistics response, with long delivery delays, excess of back orders, customer complaints, and bad marketing image. This requires a careful matching of marketing objectives and logistics capabilities.

One of the customers' more frequent complaints in the e-commerce is about missing products in a order. Because e-commerce is a time-saving service, and not merely a shopping service (Caltagirone, 2000), out-of-stocks are sometimes unacceptable to customers. If the customer submits an order containing a list of products intended to function together, the partial-fulfilled order may force him to an unexpected shopping travel. For example, when someone orders all of the ingredients for a dinner party from a dot-com supermarket, and some of them are not available, the person still has to run out to shop, impairing the seller's image. This means that customers' expectations in the e-commerce are higher than in the traditional business. This is an additional challenge to logistics managers acting in the e-commerce supply chain.

\section{TYPIFYING THE e-COMMERCE PATRON}

In order to discuss Logistics requirements for the e-Commerce, it is important to understand the preferences, habits and restrictions of prospective customers, at least to some extent, limited as we are by the available statistics. 
Table 1 shows some statistics on the world-wide commerce in the Internet. Specifically for the B2C e-commerce, the International Data Corporation (2000) estimates that the world-wide revenues will be US\$ 59 billion in 2000, reaching about US\$ 210 billion in 2003, a dramatic growth of $52 \%$ a year. This growth is mainly due to an increase in both the number of on-line transactions and the dollar value of these transactions. But the question of who are the people that use the Web, their usage habits, and their socio-economic characteristics, is not easy to answer, although some estimates are available. In 1998, approximately half of the people who used the Web with some frequency lived in the US. Presently, although there are many initiatives to enlarge access to the Web, as for instance in public schools and libraries, actual users in the US are skewed toward young males, usually college graduate, in his early or mid-thirties, engaged in an information technology or professional occupation (Machfoedy and Aistrich, 1999). As shown in Table 2, the distribution of Web users' according to sex, age, education background and profession, is still changing and does not seem to have reached an equilibrium yet.

Table 1 - Evolution of world-wide Internet commerce

\begin{tabular}{|c|c|c|}
\hline Year & $\begin{array}{c}\text { World-wide } \\
\text { Commerce run in } \\
\text { the Internet (US\$ } \\
\text { Billion) }\end{array}$ & $\begin{array}{c}\text { Web buyers } \\
\text { (million) }\end{array}$ \\
\hline 1995 & 1.1 & 3.9 \\
\hline 1996 & 5.4 & 9.0 \\
\hline 1997 & 20.7 & 17.9 \\
\hline 1998 & 39.9 & 25.1 \\
\hline 1999 & 71.2 & 35.0 \\
\hline 2000 & 116.8 & 45.7 \\
\hline
\end{tabular}

Source: Machfoedy and Aistrich (1999)

The B2C worldwide e-commerce revenues will reach about 59 billion dollars in the year 2000, Europe being responsible for $13.8 \%$ of the total. For 2003 it is expected a worldwide volume of about 210 billion dollars, from which $19.9 \%$ will be in Europe (International Data Corporation, 2000). In Latin America not more than 700 million dollars a year is spent in the B2C commerce (Bamford, 1997). Brazil, presently with 157 million inhabitants, has about 3.2 million Internet users, of which $24 \%$ are potential e-commerce consumers (Vassalo, 1999).

As compared to other Latin America countries, Brazil is far ahead in terms of Internet business, however (Figure 1). A study prepared by the Boston Consulting Group/Visa International in 1999 (Folha de São Paulo, 1999) indicated a figure of about US\$ 77 million for the e-commerce in Brazil for that year (B2C only). This figure represents $88 \%$ of Latin America's sales, while Mexico is responsible for $6 \%$, and Argentina only $2 \%$. Projections indicate a sharp increase, with e-commerce in Brazil reaching approximately US\$3.8 billion per year, by 2003 .

Sales distribution among products and services in Latin America is shown in Table 3. The supermarket business sector, which has aggressively acted in Brazil during the last few years, with a significant number of mergers and acquisitions, was 
Table 2 - Socio-economic characteristics of US Web users

\begin{tabular}{|l|c|c|c|}
\hline Socio-economic characteristics & Oct. 1995 & April 1998 & $\begin{array}{c}\text { US } \\
\text { Average }\end{array}$ \\
\hline Male/Female (\%) & $70 / 30$ & $61 / 39$ & $49 / 51$ \\
\hline Median Age & 32.7 & 35.1 & 33 \\
\hline Education (College degree or higher - \%) & 55 & 55 & 22 \\
\hline Median household income (US\$) & 63,000 & 52,500 & 31,000 \\
\hline Occupation (Professional/Management - \%) & & & \\
\hline
\end{tabular}

Source: Machfoedy and Aistrich (1999)

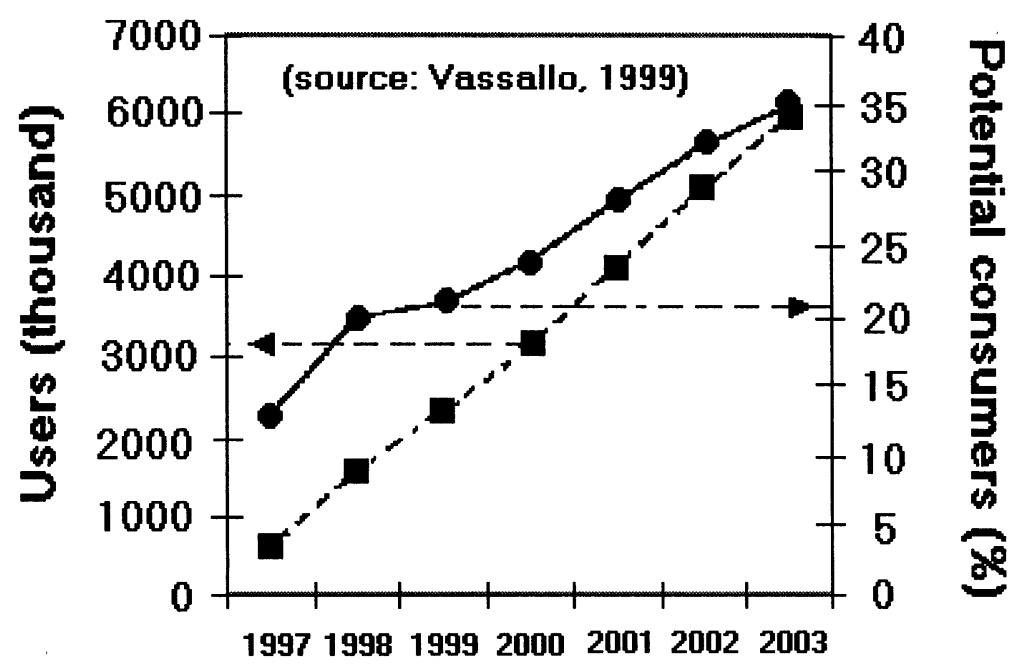

Figure 1 - Internet users and potential e-consumers in Brazil

responsible for $40 \%$ of Internet sales in Latin America, in 1999. Book sales follow with about $22 \%$, computers and software coming next with about $8 \%$. One can observe, in Table 3, that the simple display of products and services in the Web does not mean immediate sale results. Personal computers, for instance, carry higher values per purchase and naturally should show a higher yield per site. But, exactly because of the monetary figures involved, buyers are more careful when shopping, with many consulting and browsing before settling for a final choice.

The e-commerce in Brazil has to overcome certain psychological barriers before it really takes off. First, there is a deep lack of confidence toward firms that sell via telemarketing, mail order or even Internet. Mail order catalog shopping, for instance, 
Table 3 - E-commerce in Latin America per business activity

\begin{tabular}{|l|c|c|}
\hline Business activity & $\begin{array}{c}\text { Participation } \\
\text { in the Internet } \\
\text { sales, 1999 } \\
(\%)\end{array}$ & $\begin{array}{c}\text { Participation in } \\
\text { the number of } \\
\text { sites (\%) }\end{array}$ \\
\hline Supermarket & 40.2 & 3.6 \\
\hline Books & 22.1 & 19.2 \\
\hline Personal computers and software & 7.8 & 14.0 \\
\hline Other electronic products & 6.5 & 5.2 \\
\hline Music (CDs, etc) & 5.2 & 14.0 \\
\hline Banking & 3.9 & 5.2 \\
\hline Other & 14.3 & 38.8 \\
\hline
\end{tabular}

Source: Folhạ de São Paulo, 1999.

which generates from 80 to 90 billion dollars in revenue in the U.S. (Gordon, 1995), has an insignificant business participation in Brazil. All this is due not only to credit card falsifications, which is a common fact in the whole world, but it is also motivated by a lack of confidence in the seller's honesty and in the distribution system which is supposed to take the desired product to the customer, at the expected time. In Brazil, the media constantly broadcasts cases in which buyers complain about ghost firms that advertise services and products, but do not hand them to the customers, amassing large amounts of money and fleeing prior to the Police arrival. Even the mail system, which has improved a lot in the last years and operates a courier service in the country, does not receive full credit from its users.

In addition to these psychological restrictions, there is not in Brazil a nationwide, high-standard, express-delivery service such as FedEx, UPS and DHL. These firms are not authorized to operate in the internal market, restraining their operations to international flows, to and from the country. The existence of services of that kind would give a solid logistics base to the e-commerce.

\section{LOGISTICS SUPPORT TO THE A-COMMERCE}

Although some large e-business firms may prefer to implement their private delivery services, the majority will use third-party systems, such as the mail (courier), and express-delivery services. In the US, the hub-and-spoke concept put to work by Federal Express, has brought new standards to the parcel-transport sector in the US. On the one hand, with uniform delivery-time services covering thousands of connections in the US, the client is able to plan his activities more effectively, reducing costs and keeping his marketing standards. On the other hand, a nationwide delivery system of this kind, opens the opportunity for the user firms to dramatically reduce inventories. This is achieved by reducing stock points to a few distribution centers, and deploying products from these points to the consumer, via an express-delivery service. Unfortunately, Brazil does not have a similar courier service so far, besides the one run by the government-operated mail system. Next, 
we discuss some aspects related to this subject, focussing the Brazilian situation and possible solutions to the problem.

\subsection{Express-Delivery Services}

Although UPS - United Parcel Service - initiated its operations back in 1907, in Seattle, being today one of the largest parcel carriers of the world, its competitor, Federal Express, has the merit of having revolutionized this sector with modern logistics concepts. Federal Express, FedEx for short, began its operations in 1973, with headquarters in Memphis, Tennessee, serving 210 countries around the world, with an annual income of about 14 billion dollars, and delivering more than 3.1 million parcels world-wide, per day. FedEx put into practice, in the US, the concept of a national hub-and-spoke airfreight network. The concept is quite simple. FedDex couriers located around the US, pick up the parcels and take them to a local agency. From each main city of the country, the parcels are carried by air to the central hub, located in Memphis. Memphis was selected because it is centrally located in the US and airport operations are rarely impaired by bad weather. At the hub, packages are unloaded from the aircrafts, sorted according to the destinations, reloaded into the planes, and flown to their final addresses. The packages are then delivered by couriers driving FedEx vehicles.

The FedEx Priority Overnight service guarantees the delivery of packages up to $68 \mathrm{~kg}$ (150 pounds), the next business day, by 10:30 a.m. It covers thousands of U.S. cities. For the towns not served by such a service, the parcel is delivered the next business day, by noon. These features are extremely important as far as Logistics is concerned. Office hours start at 9:00 a.m. in the US, and secretaries are busy organizing their desk up to 10:00/10:30 a.m. Hence, the time window selected by FedEx to deliver the shipments suits the American business needs almost a hundred percent. And, of course, deliveries tend to distribute over time, making an exception the ones handled close to 10:30 a.m. Other less expensive FedEx services, with longer lead time, are also available.

With a money-back guarantee service, as the FedEx Priority Overnight, the clients are able to better coordinate their day-to-day operations. Above all, inventory levels can be drastically reduced. Take, for instance, the traditional book-selling business segment. If every bookstore would carry an inventory of at least two or three copies of each title, the overall inventory would be quite large. By keeping a centralized inventory, and shipping products via an express delivery system, firms are able to reduce costs, at same time satisfying their client's needs.

FedEx, UPS, DHL, and other couriers operate in Brazil, but they are limited to international shipments. FedEx established partnership with a few Brazilian carriers to handle the national leg of the courier service. But there is not an efficient, nationwide, express-delivery system operating locally in Brazil, as the one mentioned above.

A Brazilian airline, Vasp, started an express delivery service some years ago, called VaspEx, covering all the Brazilian territory. In order to organize the courier service, Vasp attracted some executives from ECT, the Brazilian postal service. The new system had a good start, at least externally, with an agile pick-up service, intensive marketing, and bar-code information retrieval. But operations lacked the minimum expected service level, due to ill organization and airline financial 
troubles. Today, the airline has entered a pre-bankruptcy phase, and the courier service is bound to be out of the market soon.

\subsection{Mail Courier Services}

The Brazilian mail system is operated by the state-owned ECT organization, which offers a express delivery service called Sedex. In 1998, Sedex handled a total of 69.5 million shipments, a timid volume when compared to its main international counterparts. The main Sedex service covers all the Brazilian territory, delivering parcels up to $30 \mathrm{~kg}$. The lead time for this service varies. From a state capital to another state capital, the Sedex system delivers the shipment on the next day, without any commitment to the hour of delivery. If the package is shipped from a state capital and is bound to the hinterland of the same state, the lead time is also one day. If, however, the origin is a state capital and the destination lies in the hinterland of another state, it is necessary one additional day to carry the shipment. The same occurs when the origin and the destination are located in the hinterland of a same state. Finally, if the point of origin and the point of destination are located in the hinterland of two different states, the service takes 3 days. Exception is the "Sedex VIP", serving the main cities of the country (Brasília, São Paulo, Rio de Janeiro, and Belo Horizonte), under which the parcel is delivered on the same day. ECT is also starting a courier service to expedite export packages up to $30 \mathrm{~kg}$ and US $\$ 10,000$ per shipment.

It is interesting to observe one important difference between ECT's Sedex and the corresponding FedEx service in the US. With many manufactures and service firms being transferred or located in smaller towns, it is highly desirable for the Economy as a whole, that express delivery services, among other equally important services, be uniformly offered over the country. Remote areas and less important towns may, of course, be bypassed, as it is actually done in the US by the existing express-delivery services. But the rules that define the territory coverage of a system of this kind should be the ones imposed by the market, not the ones intended only to optimize the carrier operations.

Although the mail courier service in Brazil is adequate to handle low volume flows, it is not suited to handle a massive increase in demand, with new service requirements as the ones imposed by the e-commerce. In the next section we discuss an alternate possibility of implementing a nation-wide courier service in Brazil.

\section{A NEW PROPOSITION}

In Brazil, the most popular transportation mode to carry people regionally is the bus system. The highway network in Brazil is presently under a rehabilitation process, with the main links being transferred to private operators and offering better service levels. Intercity bus lines cover all the Brazilian territory, with a good supply of frequencies in most links. In Europe, the railroad network performs this role of supplying a reliable, territory-wide passenger transportation service.

Being the most important intercity people-carrying mode in Brazil, it is surprising to realize that almost no reliable data are available on it. The most recent information on the subject is from 1996, showed in Table 4, with data published by tional Transport Confederation, and unfortunately covering no more than a 
month. Transportation statistics released by GEIPOT, the Ministry of Transportation's planning agency, do not cover this mode. The reason is that it is regulated and controlled regionally by the states that compose the Brazilian federation. Important information such as extension of the lines, supply of services (seat-km offered, for instance), passenger-km carried, among other, is not available for the country as a whole. Regional statistics, on the other hand, are not always reliable. Interstate links, which are regulated and controlled by the Ministry of Transportation, are also not covered in the official statistics. Despite these limitations, this mode of transportation performs an important role in Brazil.

Table 4 - Bus intercity passenger transportation in Brazil (February 1996)

\begin{tabular}{|l|c|c|c|c|c|c|}
\hline & \multicolumn{3}{|c|}{ Passengers carried (thousand) } & \multicolumn{3}{c|}{ Passenger-km (million) } \\
\hline Region & Interstate & Intrastate & Total & Interstate & Intrastate & Total \\
\hline Northeast & 965 & 24,664 & 25,628 & 2,044 & 879 & 2,923 \\
\hline $\begin{array}{l}\text { West, } \\
\text { Center }\end{array}$ & 9,089 & 5,002 & 14,091 & 1,036 & 476 & 1,513 \\
\hline Southeast & 30,728 & 201,995 & 232,723 & 10,801 & 8,564 & 19,365 \\
\hline South & 9,880 & 23,870 & 33,750 & 2,057 & 3.595 & 5,652 \\
\hline Total & 50,662 & 255,531 & 306,192 & 15,938 & 13,514 & 29,453 \\
\hline
\end{tabular}

Source: National Transport Confederation (2000)

New intercity bus bodies in Brazil have a higher passenger floor, giving way to larger luggage compartments. Since in most links people are carrying less baggage, intercity bus operators are using the remaining space to carry parcel cargo. Trucking operators are against such a practice, of course, stating it is not fair competition, since passengers pay for the service fully, letting the marginal cost of carrying parcels in busses practically nil. Some of the state agencies, on the other hand, are considering the possibility of forcing operators to reduce passenger tariffs in order to compensate for the cargo accrued revenues. All of this is due to an excessive regulated situation, in which tariffs, links, type of services, frequencies and so on, are all controlled by the local governments. Of course, if this sector is deregulated to some extent, the trend is to have its features and tariffs accommodated by the market.

Less-than-truckload operators in Brazil, with a very few exceptions, have not upgraded their services as to comply with the basic logistics requirement that delivery times must be predefined and always honored. Intercity bus services, by its own nature, have fixed territory coverage and fixed schedules. Since cargo space is available, only initiative and organization are demanded to implement an efficient express-delivery system covering the country. Due to the large number of intercitybus operators, it is not feasible to let them organize and operate the system by themselves. In fact, since a good part of the bus connections involve different carriers, the necessary integration (information, responsibility, tariffs, operations) would be the critical point to be marshaled. Our idea is to create a firm that would 
start up an express-delivery system, selling it to the public and, at the same time, buying the cargo-carrying capacity from the bus operators. The latter would only provide the transportation, not the logistics service, which would be supplied by the specialized company. It is clear that an all-bus system would impose unacceptable time spans over long-distance links. As the system grows, air links would be added, connecting the main capitals and feeding the bus network.

Although bus lines are already used for cargo carrying purposes in Brazil, the innovation in the proposed approach would be the complete reorganization of such a service under a "virtual" point of view (Clarke, 1998; Crowley, 1998). Under this concept, what matters is not where the asset is located, but whether the relevant asset can be made available when required (Clarke, 1998).

\section{CONCLUSIONS}

The Web is accelerating the process of turning the world into a global village. In fact, new habits and demands that have been originated in the developed countries are quickly reaching the developing regions. Logistics infrastructure, however, must be re-engineered before e-commerce really takes off. One possibility is to grant permission to world-wide express-delivery firms, like FedDex, UPS, DHL, and TNT, operate internally in the Brazilian territory. The other possibility, as suggested in this text, is to make an intelligent use of the excess-capacity showed by the intercity bus system to fulfil the gap.

\section{REFERENCES}

Aldrich, D.F. Mastering the Digital Marketplace, AT Kearney, www.atkearney.com, USA, 1999.

Bamford, R.S. Internet-Based Electronic Commerce in 1997: a Primer. Research Note SM-36, Graduate School of Business - Stanford University, September 1997.

Caltagirone, J.A. Peapod's Virtual Supermarket, Supply Chain Management Review, March/April 2000, 44-50.

Clarke, M.P. Virtual Logistics: an Introduction and Overview of the Concepts, International Journal of Physical Distribution \& Logistics Management 1998; 28: 486-507.

Crowley, J.A. Virtual Logistics: Transport in the Marketspace, International Journal of Physical Distribution \& Logistics Management 1998; 28: 547-74.

Folha de São Paulo. Sales on Line in Latin America Reach US\$ 77 million (in Portuguese), August $4^{\text {th }}$, 1999.

Gordon, D.S. Note on the Mail Order Industry, Harvard Business School publication n ${ }^{\circ}$ 9-595-014, 1995.

International Data Corporation. Europe Leaps to eCommerce, eBusiness Trends, May 18, 2000.

Machfoedy, A.A. and Aistrich, M. Note on Marketing and the World Wide Web, Harvard Business School publication $\mathrm{n}^{\circ}$ 9-597-037, 1999.

Moakley, G. "eCommerce Requires Intelligent Supply Chain", in Achieving Supply Chain Excellence Through Technology, Andersen Consulting, ed., 188-191, www.ascet.com, 1999.

Moon, Y. Network Technology and the Role of Intermediaries, Harvard Business School publication $\mathrm{n}^{\circ}$ 9-599-102, 2000.

National Transport Confederation (CNT), homepage www.cnt.org.br, July 2000.

Rebouças, L. The Return of the Milk-Man (in Portuguese), Exame, São Paulo, Brazil, March 8, 2000.

Vassalo, C. He Intends to Dominate The Electronic Commerce in Brazil (in Portuguese), Exame, São Paulo, Brazil, September 22, 1999. 